See Article page $\mathrm{XXX}$.

\section{Commentary: The ultimate fundamental competency: Changing with the times}

\author{
Howard K. Song, MD, PhD
}

Transcatheter aortic valve replacement (TAVR) procedures have steadily increased in frequency since the first TAVR device was approved in the United States during 2011. More than 300,000 patients have undergone TAVR in the United States and in 2019 TAVR procedure volumes exceeded all forms of surgical AVR for the first time. TAVR is clearly a central component of the treatment of patients with severe aortic stenosis. Cardiac surgeons continue to be a required participant in TAVR programs in the United States, both as a member of a multidisciplinary heart team and as a TAVR proceduralist. This participation is mandated by the Centers for Medicare and Medicaid Services and recommended by expert consensus. ${ }^{2,3}$

The protected status of cardiac surgeons in TAVR programs is based on their expertise in the surgical treatment of aortic valve disease, not necessarily their expertise in the transcatheter treatment of aortic valve disease. In fact, cardiothoracic surgery residents are only required to perform 5 TAVR procedures as primary surgeon by the American Board of Thoracic Surgery before graduating. The field of structural heart disease treatment has obviously evolved significantly since this American Board of Thoracic Surgery TAVR case requirement was made in 2017 and there is a clear-cut need for cardiothoracic surgery training programs to evolve with the field. Moran and colleagues ${ }^{4}$ make an important first step in this evolution by identifying fundamental competencies for transcatheter cardiac surgery. I can imagine that these competencies, which

\footnotetext{
From the Division of Cardiothoracic Surgery, Knight Cardiovascular Institute, Oregon Health and Science University, Portland, Ore.

Disclosures: Dr Song serves as a consultant for Edwards Lifesciences and Medtronic.

The Journal policy requires editors and reviewers to disclose conflicts of interest and to decline handling or reviewing manuscripts for which they may have a conflict of interest. The editors and reviewers of this article have no conflicts of interest.

Received for publication Aug 8, 2021; revisions received Aug 8, 2021; accepted for publication Aug 9, 2021.

Address for reprints: Howard K. Song, MD, PhD, Division of Cardiothoracic Surgery, Knight Cardiovascular Institute, Oregon Health and Science University, 3181 SW Sam Jackson Park Rd, Portland, OR 97239 (E-mail: songh@ohsu.edu).

J Thorac Cardiovasc Surg 2021; $\mathbf{\square}: 1-2$

$0022-5223 / \$ 36.00$

Copyright (C) 2021 by The American Association for Thoracic Surgery

https://doi.org/10.1016/j.jtcvs.2021.08.015
}

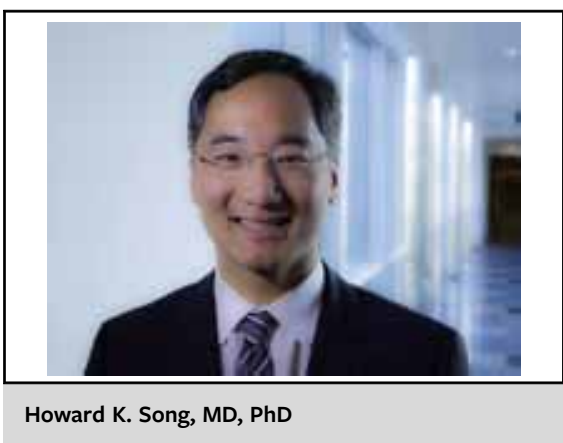

CENTRAL MESSAGE

Heart valve treatment has

evolved substantially. Cardiac

surgery training needs to evolve

to a similar degree to preserve

the place of cardiac surgeons on

heart valve teams.

were identified by a multidisciplinary panel with appropriate expertise, will be used as a resource by program directors, faculty, and professional societies and boards as they seek to set training standards that keep up with modern cardiac surgery practice.

This contribution is timely because of the dramatic changes in structural heart disease treatment and also because the status of cardiac surgeons as transcatheter proceduralists is unlikely to remain protected by Centers for Medicare and Medicaid Services and professional societies for much longer. Because of their TAVR and edge-to-edge mitral repair experience, cardiologists have rapidly developed impressive expertise in heart valve disease treatment and are rightly considered experts in the field. Structural heart disease fellowships have proliferated rapidly and are churning out cardiologists with specific training in transcatheter structural heart disease treatment and experience with hundreds of transcatheter structural heart procedures. The result is that cardiac surgeons are no longer solely qualified to assess the preparation of other surgeons to perform heart valve procedures-in many instances cardiologists can make this assessment also.

If cardiac surgeons wish to remain involved with the growing field of transcatheter treatments of heart valve disease, their training needs to evolve with the field. Moran and colleagues ${ }^{4}$ have made a good first step in this regard. The culmination of this process would be development of a structural heart curriculum that provides an accredited 
pathway for cardiologists and cardiac surgeons to be trained as valve proceduralists. This is the training model most likely to preserve a broad, multidisciplinary team approach to heart valve disease treatment.

\section{References}

1. Carroll JD, Mack MJ, Vemulapalli S, Herrmann HC, Gleason TG, Hanzel G, et al. STS-ACC TVT registry of transcatheter aortic valve replacement: state-of-the-art review. J Am Coll Cardiol. 2020;76:2492-516.

2. Medicare Coverage Database. Decision memo for transcatheter aortic valve replacement (TAVR) (CAG-00430R). 2019. Available at: https://www.cms. gov/medicare-coverage-database/details/nca-decision-memo.aspx $?$ NCAId=293. Accessed August 17, 2021.

3. Bavaria JE, Tommaso CL, Brindis RG, Carroll JD, Deeb GM, Feldman TE, et al. 2018 AATS/ACC/SCAI/STS expert consensus systems of care document: operator and institutional recommendations and requirements for transcatheter aortic valve replacement: a joint report of the American Association for Thoracic Surgery, American College of Cardiology, Society for Cardiovascular Angiography and Interventions, and Society of Thoracic Surgeons. J Am Coll Cardiol. 2019; 73:340-74.

4. Moran HRM, Maurice-Ventouris M, Alharbi M, Ahn BT, Harley JM, Lachapelle KJ. Pan-Canadian initiative on fundamental competencies for transcatheter cardiac surgery: a modified Delphi consensus study. J Thorac Cardiovasc Surg. 2021;XX:XX-XXX. 